\title{
The Use of Pulsed Field Gel Electrophoresis in Listeria monocytogenes Sub-Typing - Harmonization at the European Union Level
}

\author{
Benjamin Félix, Trinh Tam Dao, Bertrand Lombard, \\ Adrien Asséré Anne Brisabois and Sophie Roussel \\ ANSES, French Agency for Food, Environmental and Occupational Health and Safety, \\ Maisons, Alfort Laboratory for Food Safety, \\ European Union Reference Laboratory for Listeria monocytogenes,
}

France

\section{Introduction}

Agarose gel electrophoresis is commonly used for separation of DNA molecules in molecular biology research and bacterial characterization in particular. It separates DNA fragments by size. It is widely used to detect PCR amplification products or determine DNA restriction genetic profiles. Consequently it is used in most of the bacteria characterization methods.

Pulsed Field Gel Electrophoresis (PFGE) has been widely applied to characterize numerous bacteria. PFGE is a form of RFLP typing in which the bacterial genome is digested with rare cutting enzymes. These restriction enzymes cut genomic DNA infrequently and thus generate a smaller number of DNA fragments (10-20 bands). These fragments of a wide range of sizes, from $20 \mathrm{~kb}$ to 10,000 $\mathrm{kb}$ (Herschleb et al., 2007), are separated using specialized electrophoresis techniques. Differences in the restriction profiles are used to carry out genetic comparisons among isolates. Computer-based analysis is simplified, enabling rapid and easy comparison on strains. Currently, PFGE is often considered the"gold standard" of molecular typing methods for bacterial foodborne pathogens such as Salmonella, E.coli, Campylobacter, Yersinia, Vibrio and Listeria.

The food-borne disease caused by Listeria monocytogenes (L. monocytogenes) is one of the main public health concerns in Europe (Allerberger \& Wagner, 2010; EFSA, 2010; Goulet et al., 2008). Outbreaks and related clusters have to be detected as quickly as possible in order to improve the surveillance and control of this pathogen. Among the molecular methods used for sub-typing L. monocytogenes, PFGE has been widely applied to characterize food and human isolates over the last ten years (Brosch et al., 1996). Due to its high discriminating power and epidemiological relevance, this method has become the "gold standard" for $L$. monocytogenes sub-typing (Graves \& Swaminathan, 2001).

One way to accelerate the recognition of clusters common to food and human isolates requires that significant number of isolates was sub-typed by laboratories involved in its surveillance. A standardized protocol was developed by the Center for Disease Control and Prevention (CDC) in Atlanta USA (PulseNet) and has been largely used at the international 
level (Graves \& Swaminathan, 2001). Several surveillance networks currently work throughout the world using this protocol (Gerner-Smidt et al., 2006; Pagotto et al., 2006). These networks have proven their efficiency for an early detection and a better understanding of L. monocytogenes outbreaks (CDC, 2010; CDC, 2011; Gilmour et al., 2010).

In Europe, in the frame of PulseNet Europe project, two PFGE sub-typing inter-laboratory trials were carried out in 2003 and 2006 (Brisabois et al., 2007; Martin et al., 2006). The resulting PFGE data demonstrated that PFGE profiles can be compared and exchanged between laboratories. However, PulseNet Europe has not been active since November 2006 due to a lack of funding (Swaminathan et al., 2006). Moreover, in the PulseNet Europe subtyping inter-laboratory trials, only quality and interpretability of the profiles were assessed (Martin et al., 2006). Profile interpretation was not evaluated and remains difficult to standardize, in particular when dealing with a wide range of profiles including large bands, double peaks and uncertain bands.

PulseNet USA has developed standard operating procedures (SOP) for computer-assisted PFGE profile analysis using BioNumerics software (Applied Maths, Sint-Martens-Latem, Belgium) (Gerner-Smidt et al., 1998). The SOP has evolved toward an automated interpretation process. However, some steps still require the user to make critical decision during the analysis, in particular for (1) abnormal band assignment and (2) closely related profile interpretation. This crucial step is a major drawback of PFGE and its improvement remains a challenge for PFGE standardization (Gerner-Smidt et al. 2006).

In 2006, the ANSES Maisons-Alfort Laboratory for Food Safety has been designated European Union Reference Laboratory (EURL) for L. monocytogenes. It coordinates a network of 29 National Reference Laboratories (NRLs) representing 27 Member States as well as Norway. Most of them are in charge, amongst other tasks, of typing food, environmental and veterinary L. monocytogenes strains isolated at national level.

One of the EURL objectives was to harmonize PFGE protocols used by the European food NRLs. This article first describes, the principle of PFGE applied to L. monocytogenes and the relationship between a PFGE profile and bacteria's genetic make-up. It then explains the EURL SOP for interpreting PFGE profiles, based on PulseNet USA SOP. Finally, it focuses on the work undertaken by the EURL to stimulate NRLs to perform PFGE with a standardized protocol including an SOP for profile interpretation.

\section{Principles of PFGE - Relatedness between PFGE profiles and genetic reality}

The PFGE method starts with the extraction of the bacterial chromosomes without damaging to the DNA, by mean of a very gentle extraction procedure. The chromosomes are then restricted using a rare cutting enzyme. For L. monocytogenes, the enzymes are ApaI or AscI (Carriere et al., 1991). These restriction enzymes AscI and ApaI generate respectively between 6 to 12 and 14 to 17 fragments in the range of separation of the PFGE. The combinations of the profiles generated by the two enzymes are used to characterize the strains. A third profile generated by SmaI can be added to reinforce the analysis (Carrière et al. 1991)

The restricted DNA fragments are commonly separated in a PFGE CHEF (Contour-clamp homogeneous electric field) system (Chu et al., 1986). For L. monocytogenes, the range of separation is between 33 and $1135 \mathrm{~kb}$. The migration parameters applied depend on the bacteria species. For L. monocytogenes the established parameters are a pulse angle of $120^{\circ}$ 
and a linear switch-time ramp of 4 to $40 \mathrm{~s}$. These migration parameters have been standardized in the PulseNet USA protocol. The difference in the restriction profiles enables genetic comparisons among L. monocytogenes strains. Profiles are specific to each strain and are used as characterization data to identify them (Graves \& Swaminathan, 2001). However the restriction profiles are merely an image of the genome structure and must be interpreted as such (Tenover et al. 1995).

\section{Relationship between PFGE profiles and genetic reality}

The PFGE profiles are composed of DNA fragments separated along the PFGE migration range. Bands actually consists a huge copy number of the same DNA fragment flanked by two restriction sites. However it often happens that one band is composed of several fragments of the same size but coming from different parts of the bacterial chromosome (Singer et al. 2003). This explains why band intensity can vary along the profile depending of the number of superposed fragments in the same band.

The numbers and positions of the bands on the gel determine which bands are different or identical between different strain profiles. The first interpretation procedure defined by Tenover et al. (1995) showed that the interpretation of the number of band differences between a pair of isolates is based on the minimum number of genetic mutational events that would result in the observed number of band differences. For example, two isolates that differ by two to three bands would be considered as closely related since a single genetic event can explain this difference. More recently, researchers of the USA CDC proposed that the "Tenover" criteria were not generally applicable for investigation of all foodborne outbreaks. Genetic transfer, superposition of bands and other artifacts which might affect the relatedness of the profiles and the interpretation must be taken into account when interpreting profiles. According to the new criteria adopted for L. monocytogenes one band of difference is considered to be significant for distinguishing between two profiles (Barrett et al., 2006). However, in practice, in spite of these criteria, the interpretation requires many subjective decisions. This subjectivity increases the variability of the profiles and, consequently, affects the way in which results are interpreted (Gerner-Smidt et al. 1998).

The burden imposed by PFGE implies the application of a highly standardized protocol for the performance, interpretation and exchange of PFGE profile between centers in Europe.

\section{Standardized method developed by the EURL for PFGE sub-typing}

\subsection{PFGE protocol}

The EURL PFGE protocol developed by EURL and standardized between NRLs is similar to the newly updated PulseNet USA (PN USA) PFGE standardized protocol (Halpin et al., 2009) with minor modifications. In the PN USA extraction protocol, the cell density per plug is lower than in the EURL protocol (0.9-1.0 OD 610 PN USA against 1.6-1.8 OD 600 EURL) and consequently in proportion to the cell density, proteinase K, lysozyme, Sodium Dodecyl Sulfate and other lysis buffer reagents are used at lower concentration. The lysozyme is prepared in a TE buffer (PN USA) instead of sterile water (EURL). Lysozyme incubation is undertaken at $56^{\circ} \mathrm{C}$ (PN USA) instead of $37^{\circ} \mathrm{C}$ (EURL). The amount of restriction enzyme is higher in the PN USA protocol than in the EURL one, for AscI $0.125 \mathrm{U} / \mu \mathrm{L}$ (PN USA) instead of $0.100 \mathrm{U} / \mu \mathrm{L}$ (EURL), and for $A p a \mathrm{I} 0.250 \mathrm{U} / \mu \mathrm{L}$ (PN USA) instead of $0.100 \mathrm{U} / \mu \mathrm{L}$ (EURL). 
The reproducibility of this protocol between European NRLs has been assessed already two times at the occasion of two inter-laboratory proficiency testing trials (PT trials) in 2009 and 2010. The results obtained were satisfactory. At this time 14 NRLs, representing 14 member states, have been assessed competent by the EURL for L. monocytogenes PFGE sub-typing.

\subsection{Standard operating procedure for PFGE profile interpretation}

This method is based on the interpretation method developed by Barrett et al. (2006) and the PulseNet USA PFGE profile interpretation SOP. It includes one band of difference as the limit to consider two PFGE profiles as indistinguishable as recommended in Barrett et al (2006). It includes a down limit for band interpretation at $33 \mathrm{kbp}$, established according to EURL own experience and the conclusion drawn from the PT trial organized on Salmonella by Peters et al. (2006), and a new profile identification strategy based on database library organization (explained in detail below). This new strategy aims to reduce any artificial diversity generated by the operator's interpretation of the profile. Prior to any analysis of PFGE profiles the quality of the gel should be checked. This involves two steps: an assessment of the overall quality of the gel and an interpretation of the PFGE profiles. These two steps will be developed below.

\subsubsection{Assessment of the overall quality of the gel}

\subsubsection{Visual interpretation}

The gel should not contain background or debris which impedes interpretation of the image. Nevertheless, if only part of the image is degraded, the intact part of the gel can be analysed normally. PFGE profiles must be fully visible in order to be analysed. Gels with small spots can be interpreted if the image is first processed using image processing software to remove spots from the image. Gels must enable good contrast and should not contain any fuzzy fields that could impede the analysis. The gel should not exhibit any grossly incomplete restriction bands (figure 1). The expected number of bands must not exceed the range given in table 1. The most frequent problem with PFGE profiles is by far the apparition or disappearance of bands due to incomplete restriction of the DNA, as shown by Martin et al. (2006). This problem is most likely related to incomplete DNA restriction, which is often due to poor DNA quality. If this occurs, the contamination of reagents, buffers or purified water used during the extraction step, are the primary suspects.

\begin{tabular}{|l|l|}
\hline Enzyme & Number of bands expected \\
\hline AscI & $6-12$ \\
\hline ApaI & $14-17$ \\
\hline
\end{tabular}

Table 1. Number of bands expected for a PFGE profile of L .monocytogenes (Carrière et al., 1991)

It is sometimes difficult to detect incomplete restriction bands. They are detected when, in the upper part of the profile, the bands do not follow a descending order of intensity with respect to their molecular weight (figure 2). However an exception to this rule does not mean that the profile must be systematically rejected. Some incomplete restriction bands can be tolerated in a PFGE profile and criteria have been established for validating a profile carrying slightly incomplete restriction bands (figure 1 right). 


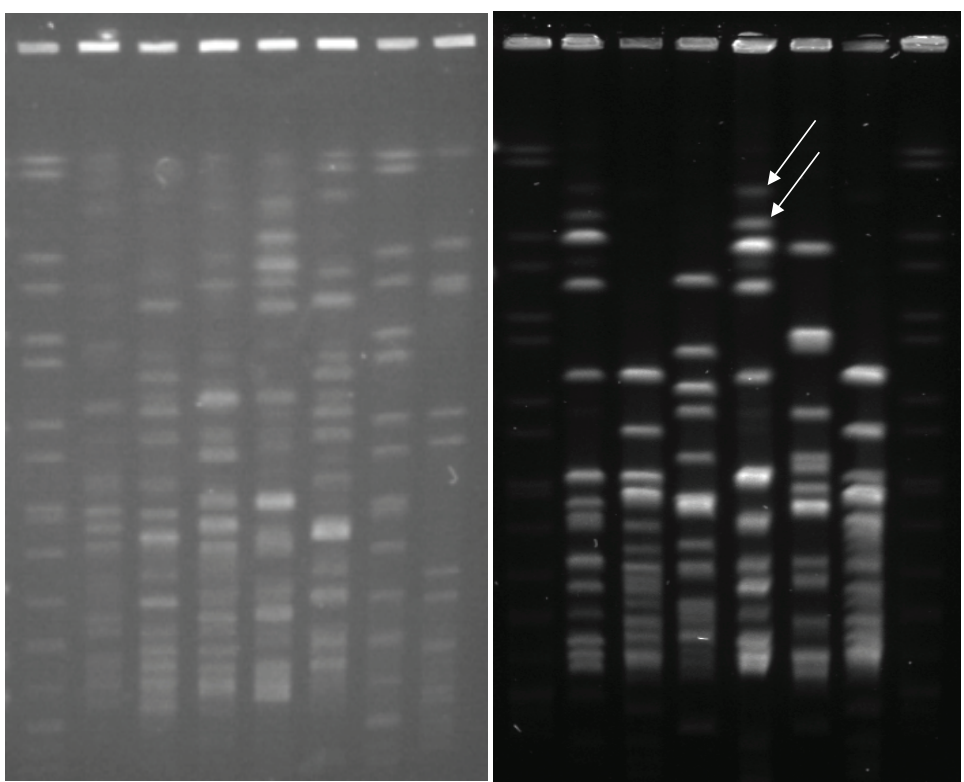

Fig. 1. Left side: ApaI restriction profile of L. monocytogenes with numerous incomplete restriction bands. Right side: ApaI restriction profile of L.monocytogenes with a few incomplete restriction bands (the white arrows indicate the doubtful bands)
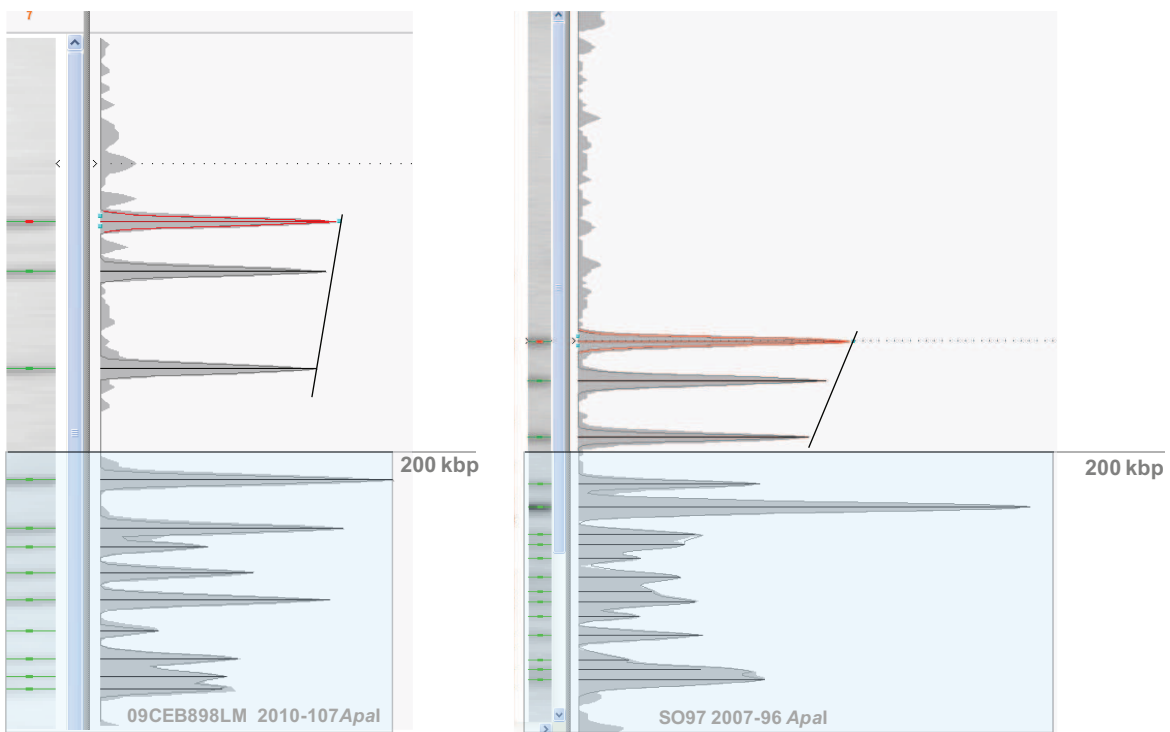

Fig. 2. Densitometric curves obtained from DNA migration profiles by mean of image processing software. The image shows two ApaI restriction profiles of L. monocytogenes. The bands in the upper part of the gel meet the criteria for arranging the upper bands by descending order of intensity. 


\subsubsection{Protocol for validation of doubtful bands in a PFGE profile}

The PFGE profile should be analysed in two parts, separated by considering, first the upper part of the profile that contains the most intense bands, composed of long DNA fragments (between 200 and $1000 \mathrm{~kb}$ ) and then the lower part of the gel which has smaller fragments (between 33 and $200 \mathrm{~kb}$ ). In the upper part there is a low probability of bands overlapping since the bands observed in this area have a high molecular weight and are few in number. In the lower part of the gel band overlapping is more likely because there are more fragments and they have of low molecular weight. The validation protocol is only applied to the upper part of the profile. A $200 \mathrm{~kb}$ separation limit was decided upon for separating the upper part and lower parts of the profile. This limit was defined empirically according to the EURL database (1500 AscI and ApaI L. monocytogenes PFGE profiles).

The validation protocol is based on an assessment of incomplete restriction bands relative to the average intensity of the profile's bands. Indeed, applied to the upper part of the profile, suspect bands (figures 3 left grey arrows) may be accepted if their intensity is less than $30 \%$ of the average intensity of the profile (figure 3 left) or above the average intensity value (figure 3 right). These limits were based on observation made on EURL PFGE profile database. Band below $30 \%$ of the average intensity resulted in a negligible incomplete restriction deviation and are tolerated. Band up to the average band intensity are not related to incomplete restriction and are accepted. The average intensity can be calculated from the band intensity values of the densitometric curve. Band intensity values can be calculated by any image processing software which features densitometric curve calculation from DNA migration profiles (e.i. see BioNumerics user manual). Rejected profiles are shown in figure 4.
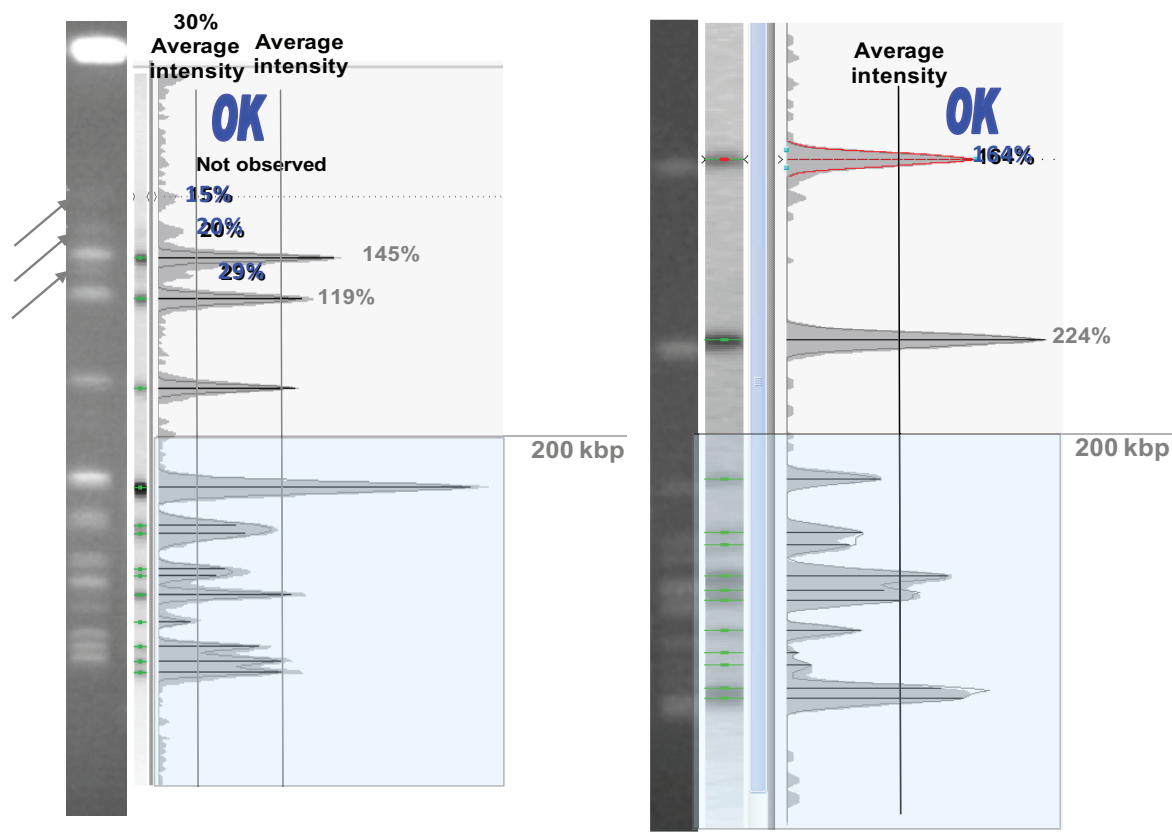

Fig. 3. ApaI restriction profiles of L. monocytogenes, carrying doubtfull bands, but which have nevertheless been accepted according to the validation protocol. 


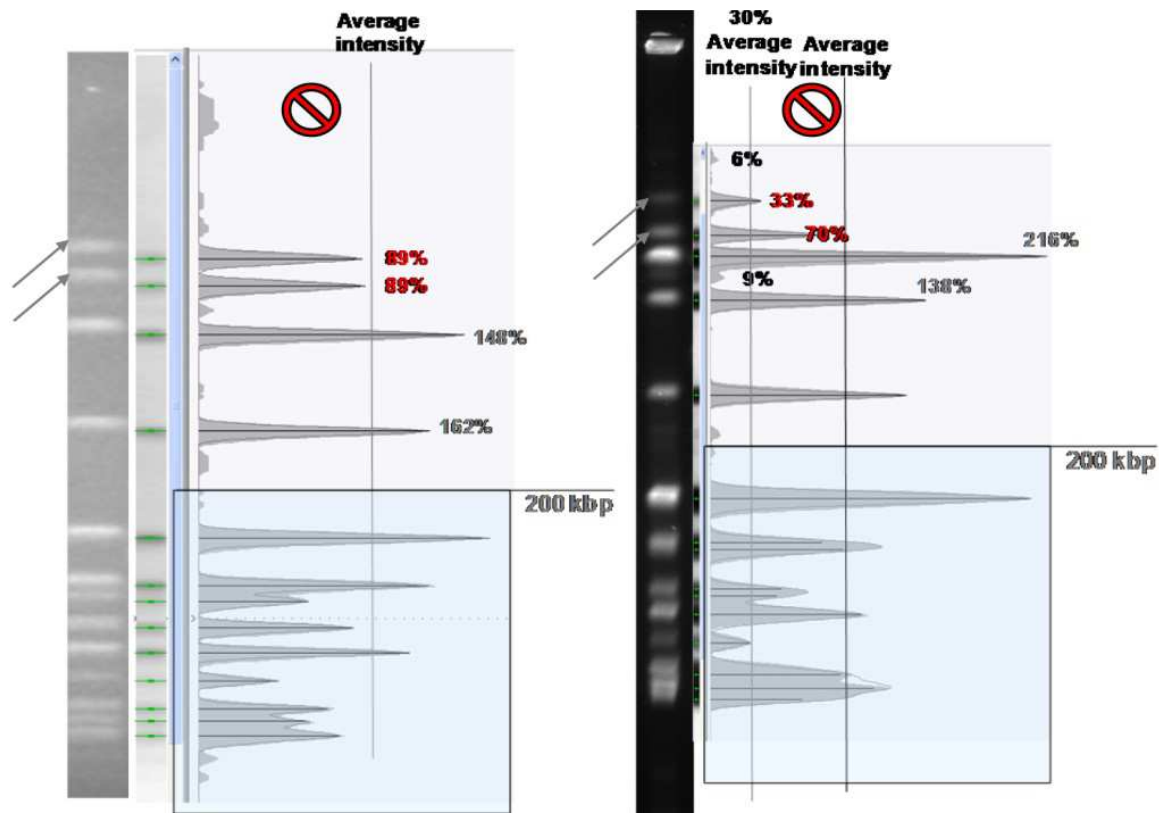

Fig. 4. ApaI restriction profiles of L. monocytogenes, carrying doubtfull bands, rejected according to the validation protocol

\subsubsection{Use of controls to validate the different stages of the analysis}

\subsection{Reference system used}

The Salmonella Braenderup (S. Braenderup) H9812 reference system was established by the USA CDC for PFGE of L. monocytogenes (figure 5 left) (Hunter et al., 2005). The former reference system, L. monocytogenes $\mathrm{H} 2446$ (figure 5 right), is still being used for extraction control by EURL, but only digested with AscI see Table 2. In both cases the reference profiles have to be visible and conducive to interpretation (figure 5), i.e., it must be possible to position all their bands precisely and the intensity of the peaks should not be at the background level. The Salmonella Braenderup H9812 XbaI digestion product must frame the analyzed profile to allow an efficient normalization process and must be run in every six lanes. L. monocytogenes H2446 AscI digestion product is loaded at the extreme left and extreme right of the gel. Moreover all set of controls must be applied to validate the reference systems as shown in Table 2.

\subsection{Migration distortion analysis}

Migration in the gel should not be distorted excessively in comparison to the standard reference system associated with the experiment in the normalization software (Here BioNumerics v6.5 Applied Maths, Sint-Martens-Latem, Belgium). For this purpose, the "Distortion bar" option of the BioNumerics software can be used (BioNumerics v6.0 user manual). Distortions are shown as colored bars (figure 6). Light colors (sky blue or yellow) indicate a lack of distortion with respect to the experiment's internal reference. Darker colors (red or bright blue) indicate a stronger distortion which may, however, be 
compensated by the software. Black coloring indicates distortion which is too great to be counteracted by the software.

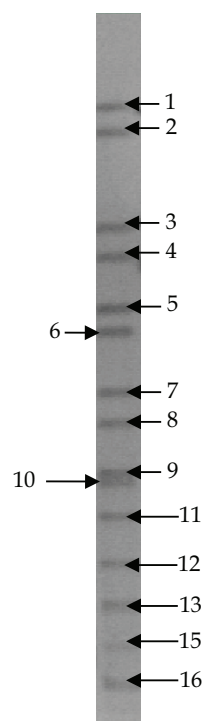

\begin{tabular}{|c|c|}
\hline $\begin{array}{c}\text { Band } \\
\text { number }\end{array}$ & $\begin{array}{c}\text { Molecular weight } \\
(\mathrm{Kb})\end{array}$ \\
\hline $\mathbf{1}$ & $\mathbf{6 9 0 . 5}$ \\
\hline 2 & 456.3 \\
\hline 3 & 397.4 \\
\hline 4 & 384.5 \\
\hline 5 & 250.2 \\
\hline 6 & $\mathbf{2 2 6 . 0}$ \\
\hline 7 & $\mathbf{1 2 1 . 6}$ \\
\hline $\mathbf{8}$ & $\mathbf{1 0 2 . 9}$ \\
\hline $\mathbf{9}$ & $\mathbf{7 2 . 1}$ \\
\hline $\mathbf{1 0}$ & $\mathbf{4 8 . 9}$ \\
\hline $\mathbf{1 1}$ & $\mathbf{4 4 . 6}$ \\
\hline $\mathbf{1 2}$ & 36.6 \\
\hline 13 & 32.8 \\
\hline 14 & 28.9 \\
\hline
\end{tabular}

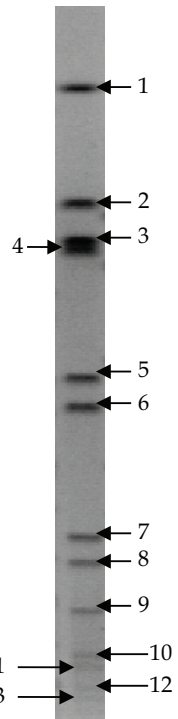

\begin{tabular}{|c|c|}
\hline Band number & $\begin{array}{c}\text { Molecular weight } \\
(\mathrm{Kb})\end{array}$ \\
\hline $\mathbf{1}$ & $\mathbf{1 1 3 5}$ \\
\hline $\mathbf{2}$ & $\mathbf{6 6 8 . 9}$ \\
\hline $\mathbf{3}$ & $\mathbf{4 5 2 . 7}$ \\
\hline $\mathbf{4}$ & $\mathbf{3 9 8 . 4}$ \\
\hline $\mathbf{5}$ & $\mathbf{3 3 6 . 5}$ \\
\hline $\mathbf{6}$ & $\mathbf{3 1 0 . 1}$ \\
\hline $\mathbf{7}$ & $\mathbf{2 4 4 . 4}$ \\
\hline $\mathbf{8}$ & $\mathbf{2 1 6 . 9}$ \\
\hline $\mathbf{9}$ & $\mathbf{1 7 3 . 4}$ \\
\hline $\mathbf{1 0}$ & $\mathbf{1 6 7 . 1}$ \\
\hline $\mathbf{1 1}$ & $\mathbf{1 3 8 . 9}$ \\
\hline $\mathbf{1 2}$ & $\mathbf{1 0 4 . 5}$ \\
\hline $\mathbf{1 3}$ & $\mathbf{7 8 . 2}$ \\
\hline 14 & 76.8 \\
\hline $\mathbf{1 5}$ & $\mathbf{5 4 . 7}$ \\
\hline $\mathbf{1 6}$ & $\mathbf{3 3 . 3}$ \\
\hline 17 & 28.8 \\
\hline 18 & 20.5 \\
\hline & \\
\hline
\end{tabular}

Fig. 5. On the left, number of bands and molecular weight obtained for S. Braenderup H9812 after digestion with the $\mathrm{XbaI}$ enzyme. On the right number of bands and molecular weight obtained for L. monocytogenes $\mathrm{H} 2446$ after digestion with the AscI enzyme. The black arrows show the bands taken into account for the analysis.

\begin{tabular}{|l|l|l|}
\hline Type of control & Strain(s) used & Expected action \\
\hline Extraction control & $\begin{array}{l}\text { L. monocytogenes H2446 and } L . \\
\text { monocytogenes H2446 strains test } \\
\text { already extracted and validated } \\
\text { during a former migration }\end{array}$ & $\begin{array}{l}\text { Extract it with the other strains of } \\
\text { the analysis. Verify that the quality } \\
\text { of the profile is similar to the former } \\
\text { extraction. }\end{array}$ \\
\hline $\begin{array}{l}\text { Control for } \\
\text { restriction with the } \\
\text { AscI enzyme }\end{array}$ & $\begin{array}{l}\text { L. monocytogenes H2446 from } \\
\text { another extraction batch }\end{array}$ & $\begin{array}{l}\text { Digest it with the extraction control } \\
\text { to check AscI restriction quality }\end{array}$ \\
\hline $\begin{array}{l}\text { Control for } \\
\text { restriction with the } \\
\text { XbaI enzyme }\end{array}$ & $\begin{array}{l}\text { S. Braenderup H9812 from } \\
\text { another extraction batch }\end{array}$ & $\begin{array}{l}\text { Digest it with S. Braenderup H9812 } \\
\text { chosen for the analysis to check } \\
\text { XbaI restriction quality }\end{array}$ \\
\hline $\begin{array}{l}\text { Control for gel } \\
\text { migration }\end{array}$ & $\begin{array}{l}\text { S. Braenderup H9812 and L. } \\
\text { monocytogenes H2446 strains } \\
\text { validated during a former } \\
\text { migration }\end{array}$ & $\begin{array}{l}\text { Verify that all bands have migrated } \\
\text { as in the former analysis }\end{array}$ \\
\hline $\begin{array}{l}\text { Control for analysis } \\
\text { with gel processing } \\
\text { software }\end{array}$ & $\begin{array}{l}\text { L.monocytogenes H2446 already } \\
\text { analysed under gel processing } \\
\text { software }\end{array}$ & $\begin{array}{l}\text { Verify that all bands can be } \\
\text { processed as made in the former } \\
\text { analysis }\end{array}$ \\
\hline
\end{tabular}

Table 2. Controls used in the analysis of L.monocytogenes strains by PFGE. 

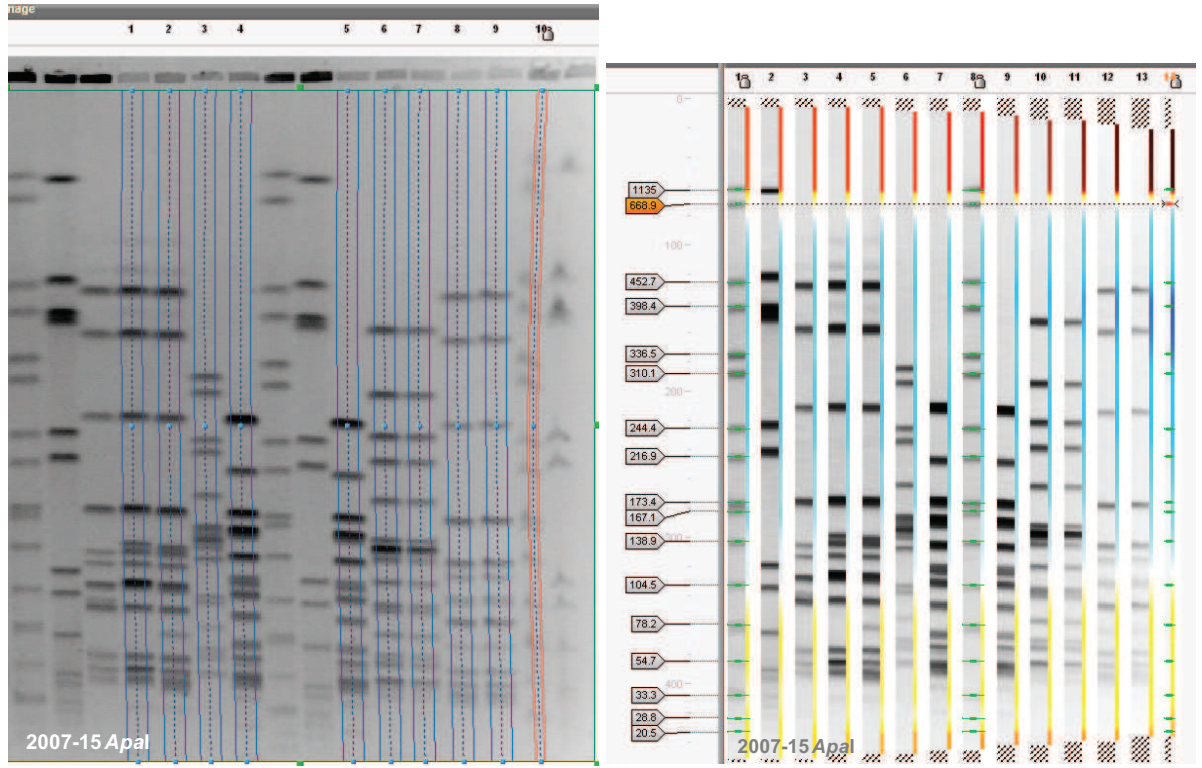

Fig. 6. S. Braenderup reference system which migrated abnormally.

\subsubsection{Interpretation of the PFGE profiles}

\subsubsection{Interpretation of profile saturated intensity area}

If a profile contains saturation zones, it cannot be interpreted. To detect this type of anomaly, the densitometric curve of the profile's bands simply needs to be displayed via the densitometric curve calculation feature (e.i. see BioNumerics user manual). Saturated peaks are shown with their tips truncated (figure 7). No saturation can be accepted in a molecular PFGE profile.

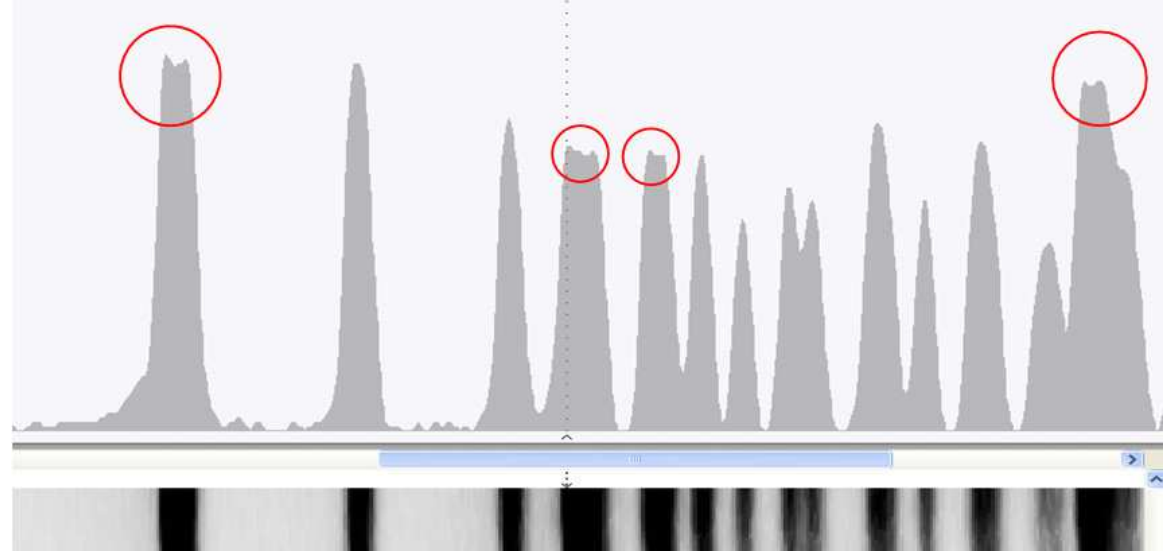

Fig. 7. PFGE profile with saturated bands (red circles). 


\subsubsection{Interpretation of molecular profiles}

Because every signal is related to the presence of DNA in the gel, molecular PFGE profiles must be interpreted objectively, as shown below, with a band on every signal (the three examples in figure 8).
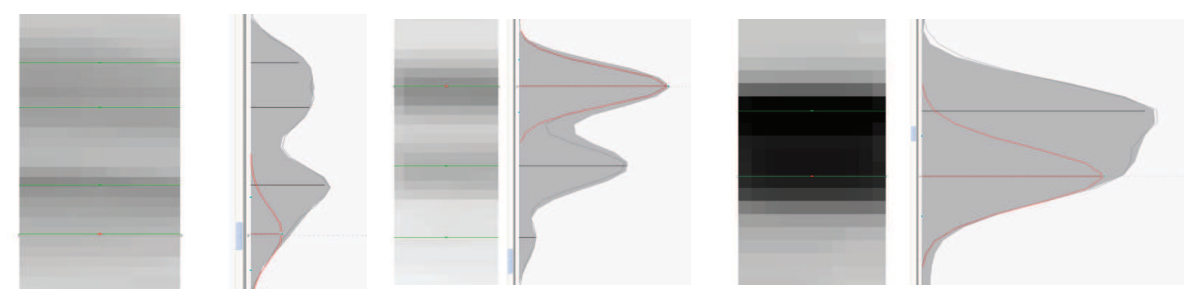

Fig. 8. Example of objective allocation of bands based on the densitometric curve of the profile.

\subsubsection{Profile analysis protocol}

The analysis begins with the marking of the bands found on the PFGE profiles, followed by the method developed by EURL to help operators to take band assignment decisions. As told before the profile identification strategy is based on the use of library identification. This method uses the whole database as a reference to assign profiles within a group of profiles similar at $90 \%$ (Also called library unit) and then allows the assignment of pulsotype number. A library is composed of several library units organized as follows. The percentage of similarity between two profiles within a library unit is calculated using the Dice coefficient, which depends on the number of bands that are common to both profiles. The determination of bands common to both profiles depends on two parameters, tolerance and optimization both set at $1 \%$ as recommended by PulseNet Europe (Martin et al., 2006). Profiles are grouped together according to the UPGMA (unweighted pair group method using arithmetic averages). This method allows profiles to be grouped according to their percentage of similarity. A library pools the profiles obtained with the same restriction enzyme according to the same PFGE protocol. For L. monocytogenes two libraries were created for ApaI and AscI profiles.

The profile interpretation step starts following the assignment of the bands on the profile. The purpose of this step is to minimize the diversity within library unit by reducing artificial diversity generated by the operator's interpretation of the profile. The first step of the interpretation starts by the comparison of the new profile against all library units. The new profile will be included in the library unit with the nearest average profile. At this stage the operator has to respect the following library unit definition: (1) verify the homogeneity of the new profile with library unit content, (2) change the new profile to match with its assigned library unit as much as possible, (3) perform profile modification within the library unit limit (90\% similarity within library unit components), (4) check that a band is always placed on a true signal and finally. The example detailed below shows how this method in applied.

In the case of the no. 17 library unit (figure 9), all the profiles have a strong signal in their central part marked by three bands (yellow rectangle). However, in some cases the shape of the signal does not enable three bands to be positioned with certainty. These bands are 
called suspect signal bands (figure 10). Thus there are two distinct profile categories in this library unit, those which allow the easy positioning of these three bands (figure 11) and the other profiles carrying suspect signals. This is in this situation, that analysis by library of profile comes into play. In this example, all the suspect profiles will be marked with the same number of bands as the clearly marked profile, but only if the suspect profiles allow the positioning of three bands on their signal (see the question marks in figure 10).

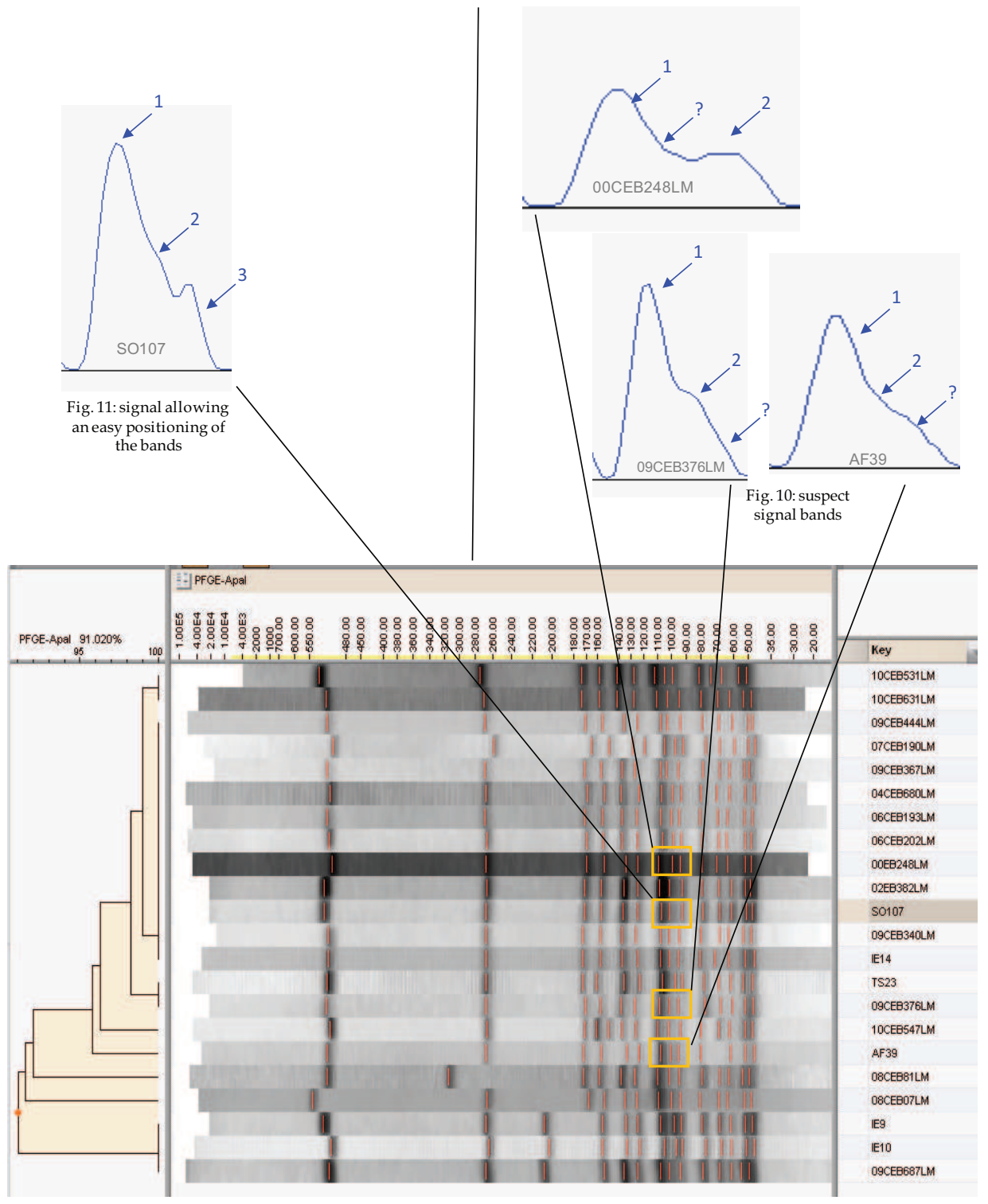

Fig. 9. ApaI library unit $\mathrm{n}^{\circ} 17$ presented entirely as a PFGE profile comparison file. 
If a profile has two clearly distinct bands in central position, and not three as for the other profiles of this library, these bands must be marked as they are and then depart from the library type profile. It will then be necessary to check that this profile is maintained clearly in the library and that it meets the library unit definition. In this example we focused on a part of the profile, however this method must be applied for every suspect signals.

Finally once the new profile has been included into the library unit it remains to be checked that there is no spanning between units 17 and another unit in the database (profile move from a library unit to another one). This verification can be made by marking the library unit on the global database dendrograms. This parallel organization of the database dendrograms and library unit allows the monitoring of database organization and integrity. The introduction of new profiles into the global database dendrograms can generate, time after time, changes in the organization of the UPGMA. These changes must be followed and checked on a regular basis (every three month at the EURL) to keep the library unit organisation consistent with the global database dendrograms. An automated script will be developed in collaboration with the software supplier to help the operator in this task.

\section{Strengthening NRLs capacity for standardized sub-typing of Listeria monocytogenes}

The EURL PFGE methods were dispatched to all NRLs. The laboratory has been certified by the French Accreditation Committee (COFRAC) for the PFGE methods since 2008 (accreditation no.1-2246, Section Laboratories, www.cofrac.fr). Annual workshops, including typing sessions, organized by EURL make stimulation of NRLs to perform PFGE. Since 2008, annual trainings has been organized by the EURL. Moreover, the EURL has organized PT trials in 2009 and 2010 to evaluate the ability of NRLs to perform conventional serotyping, molecular serotyping and PFGE. The PT trial would be renew on a regular basis. Next PT trial has been already paned for 2012.

\section{Conclusion}

The PFGE profile interpretation SOP is vital for the administration of a PFGE profile database. The published SOP deploys the process used by the curator to treat PFGE profiles. It could be followed by NRLs for their own local database organization. This SOP solves a problem caused by PFGE profile databasing, which is the introduction during the profile interpretation of an artificial diversity due to the operator in charge of the analysis. PT trials will be organized by the EURL on PFGE profile interpretation based on this SOP. The implementation of the SOP is part of the effort made by EURL to strengthen PFGE typing at European level. Once NRLs trained and evaluated on the SOP, it will be possible not only to share comparable PFGE profiles but also to share PFGE profiles normalized and marked. From the project naturally outcomes the implementation of a European PFGE database shared and filled in by the NRLs. The EURL database for $L$. monocytogenes food isolates (EURL Lm DB) was established in 2011 by EURL and is currently available for all NRLs. It enables to gather exhaustive typing and epidemiological information on L. monocytogenes strains circulating throughout the food chain across Europe. 


\section{Acknowledgements}

This work was conducted as part of the activities of the European Union Reference Laboratory for Listeria monocytogenes and was supported by a grant from the DirectorateGeneral for Heath and Consumers (DG Sanco) of the European Commission.

We thank the study group of European NRLs involved in the PT trials organized by EURL in 2009 and 2010. We also thank Susanne Thisted Lambertz from Swedish NRL for her helpful advises in the writing of this publication.

\section{References}

Allerberger, F., Wagner, M. 2010. Listeriosis: a resurgent foodborne infection. Clin Microbiol Infect 16, 16-23.

Barrett, T.J., Gerner-Smidt, P., Swaminathan, B. 2006. Interpretation of pulsed-field gel electrophoresis patterns in foodborne disease investigations and surveillance. Foodborne Pathog Dis 3, 20-31.

Brisabois, A., Kérouanton, A., Jacquet, C., Lucas, C., Hendriksen, R., Lukinmaa, S. 2007. An inter-laboratory Quality Assay of Listeria monocytogenes pulsed-field gel electrophoresis in the frame of PulseNet Europe certification, 2007 ISOPOL XVI. Savannah, Georgia, USA, Savannah.

Brosch, R., Brett, M., Catimel, B., Luchansky, J. B.,Ojeniyi, B., Rocourt, J.1996. Genomic fingerprinting of 80 strains from the WHO multicenter international typing study of Listeria monocytogenes via pulsed-field gel electrophoresis (PFGE). Int J Food Microbiol 1996; 32(3): 343-55.

Carriere, C., A. Allardet-Servent, G. Bourg, A. Audurier, M. Ramuz. 1991. DNA polymorphisme in strains of Listeria monocytogenes. J Clin Microbiol 29, 1351-1355.

CDC, USA. 2010. Outbreak of invasive listeriosis associated with the consumption of hog head cheese--Louisiana, 2010. MMWR Morb Mortal Wkly Rep 60, 401-405.

CDC 2011. Multistate outbreak of listeriosis associated with Jensen Farms cantaloupeUnited States, August-September 2011. MMWR Morb Mortal Wkly Rep; 60: 13571358.

Chu, G., Vollrath, D., Davis, R.W. 1986. Separation of large DNA molecules by contourclamped homogeneous electric fields. Science 234, 1582-1585.

EFSA. 2010. The Community Summary Report on trends and sources of zoonoses, zoonotic agents and food-borne outbreaks in the European Union in 2008. EFSA Journal 1496, 288p.

Gerner-Smidt, P., Graves, L.M., Hunter, S., Swaminathan, B. 1998. Computerized analysis of restriction fragment length polymorphism patterns: comparative evaluation of two commercial software packages. J Clin Microbiol 36, 1318-1323.

Gerner-Smidt, P., Hise, K., Kincaid, J., Hunter, S., Rolando, S., Hyytia-Trees, E., Ribot, E.M., Swaminathan, B. 2006. PulseNet USA: a five-year update. Foodborne Pathog Dis 3, 919.

Gilmour, M.W., Graham, M., Van Domselaar, G., Tyler, S., Kent, H., Trout-Yakel, K.M., Larios, O., Allen, V., Lee, B., Nadon, C. 2010. High-throughput genome sequencing of two Listeria monocytogenes clinical isolates during a large foodborne outbreak. BMC Genomics 11, 120. 
Goulet, V., Hedberg, C., Le Monnier, A., de Valk, H. 2008. Increasing incidence of listeriosis in France and other European countries. Emerg Infect Dis 14, 734-740.

Graves, L.M., Swaminathan, B. 2001. PulseNet standardized protocol for subtyping Listeria monocytogenes by macrorestriction and pulsed-field gel electrophoresis. Int J Food Microbiol 65, 55-62.

Halpin, J.L., Garrett, N.M., Ribot, E.M., Graves, L.M., Cooper, K.L. 2010. Re-evaluation, optimization, and multilaboratory validation of the PulseNet-standardized pulsedfield gel electrophoresis protocol for Listeria monocytogenes. Foodborne Pathog Dis 7, 293-298.

Herschleb, J., Ananiev, G., Schwartz, D.C. 2007. Pulsed-field gel electrophoresis. Nat Protoc 2, 677-684.

Hunter, S.B., Vauterin, P., Lambert-Fair, M.A., Van Duyne, M.S., Kubota, K., Graves, L., Wrigley, D., Barrett, T., Ribot, E. 2005. Establishment of a universal size standard strain for use with the PulseNet standardized pulsed-field gel electrophoresis protocols: converting the national databases to the new size standard. J Clin Microbiol 43, 1045-1050.

Kerouanton, A., Brisabois, A., Denoyer, E., Dilasser, F., Grout, J., Slavat, G., Picard, B. 1998. Comparison of five typing methods for the epidemiological study of Listeria monocytogenes. Int J Food Microbiol 1998; 43: 61-71.

Martin, P., Jacquet, C., Goulet, V., Vaillant, V., De Valk, H. 2006. Pulsed-field gel electrophoresis of Listeria monocytogenes strains: the PulseNet Europe Feasibility Study. Foodborne Pathog and Dis 3, 303-308.

Pagotto, F., L. K. Ng, et al. (2006). "Canadian listeriosis reference service." Foodborne Pathog Dis 3(1): 132-137.

Peters, T. M., C. Maguire, et al. (2003). "The Salm-gene project - a European collaboration for DNA fingerprinting." Euro Surveill 8(2): 46-50.

Swaminathan, B, Gerner-Smidt P, Ng, LK, et al. "Building PulseNet International: an interconnected system of laboratory networks to facilitate timely public health recognition and response to foodborne disease outbreaks and emerging foodborne diseases. Foodborne Pathog Dis 3(1): 36-50.

Tenover, F.C., Arbeit, R.D., Goering, R.V., Mickelsen, P.A., Murray, B.E., Persing, D.H., Swaminathan, B. 1995. Interpreting chromosomal DNA restriction patterns produced by pulsed-field gel electrophoresis: criteria for bacterial strain typing. J Clin Microbiol 33, 2233-2239. 


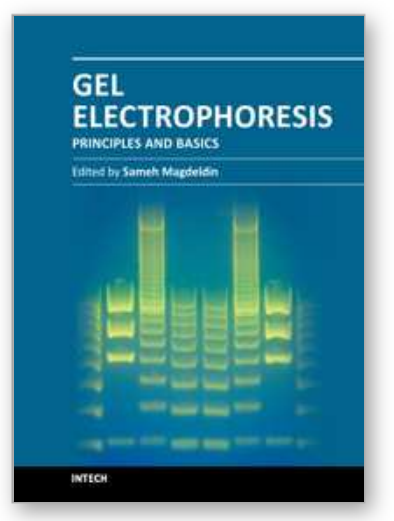

\author{
Gel Electrophoresis - Principles and Basics \\ Edited by Dr. Sameh Magdeldin
}

ISBN 978-953-51-0458-2

Hard cover, 346 pages

Publisher InTech

Published online 04, April, 2012

Published in print edition April, 2012

Most will agree that gel electrophoresis is one of the basic pillars of molecular biology. This coined terminology covers a myriad of gel-based separation approaches that rely mainly on fractionating biomolecules under electrophoretic current based mainly on the molecular weight. In this book, the authors try to present simplified fundamentals of gel-based separation together with exemplarily applications of this versatile technique. We try to keep the contents of the book crisp and comprehensive, and hope that it will receive overwhelming interest and deliver benefits and valuable information to the readers.

\title{
How to reference
}

In order to correctly reference this scholarly work, feel free to copy and paste the following:

Benjamin Felix, Trinh Tam Dao, Bertrand Lombard, Adrien Assere Anne Brisabois and Sophie Roussel (2012). The Use of Pulsed Field Gel Electrophoresis in Listeria monocytogenes Sub-Typing - Harmonization at the European Union Level, Gel Electrophoresis - Principles and Basics, Dr. Sameh Magdeldin (Ed.), ISBN: 978953-51-0458-2, InTech, Available from: http://www.intechopen.com/books/gel-electrophoresis-principles-andbasics/harmonization-of-listeria-monocytogenes-pfge-sub-typing-at-european-union-level

\section{INTECH}

open science | open minds

\section{InTech Europe}

University Campus STeP Ri Slavka Krautzeka 83/A 51000 Rijeka, Croatia Phone: +385 (51) 770447

Fax: +385 (51) 686166 www.intechopen.com

\section{InTech China}

Unit 405, Office Block, Hotel Equatorial Shanghai No.65, Yan An Road (West), Shanghai, 200040, China 中国上海市延安西路65号上海国际贵都大饭店办公楼405单元 Phone: +86-21-62489820

Fax: +86-21-62489821 
(C) 2012 The Author(s). Licensee IntechOpen. This is an open access article distributed under the terms of the Creative Commons Attribution 3.0 License, which permits unrestricted use, distribution, and reproduction in any medium, provided the original work is properly cited. 